\title{
Influence of near standing cylindrical structures on wind pressure distribution on the multispan roofs of halls
}

\author{
Ivana Veghova ${ }^{1, *}$ and Olga Hubova ${ }^{1}$ \\ ${ }^{1}$ Slovak University of Technology, Faculty of Civil Engineering, Department of Structural \\ Mechanics, Radlinského 11, 81005 Bratislava, Slovak Republic
}

\begin{abstract}
This article deals with experimental investigation of a wind pressure distribution on multispan roofs of halls. The wind pressure distribution on the structures is an important parameter in terms of wind load calculation. For multispan roofs it is possible to find these values in Eurocode 1991-1-4, but without an influence of surrounding structures. The series of parametric wind tunnel studies was carried out in BLWT to investigate the effects of in-line standing cylinders near the hall. Measurements were made in turbulent wind flow for two reference wind speeds and varying wind directions. The experimentally obtained $\mathrm{c}_{\mathrm{pe}}$ values were compared with the conservative values in EN 1991-1-4 for multispan roofs.
\end{abstract}

\section{Introduction}

The wind load depends on several factors such as wind speed and turbulence, the type of terrain, as well as the shape of the object. The structures surrounding the object also play an important role and can significantly influence and modify the wind flow and also the distribution of wind pressures on the structure. EN 1991-1-4 [1] does not take into account the influence of surrounding structures and it is therefore appropriate to objectify the external wind pressure coefficients either by CFD simulation or by experimental measurement in wind tunnels.

The aim of experimental measurements of the effect of wind on multi-pole halls was to obtain wind load values in the zones of the roof and wall, as a row of cylindrical tanks with dome roofs is located in close proximity to the hall. Stand-alone cylindrical structures create distinct suction zones on the sides and these can degrade the layout and wind load of the hall. BLWT STU tunnel [2] with modeled boundary layer allows repeated measurements for different wind directions and speeds. The influence of wind on structures in groups can be experimentally observed on scale models and the most unfavorable effects of wind on individual objects can be determined.

\footnotetext{
*Corresponding author: ivana.veghova@ stuba.sk
} 


\section{Wind load}

Effects and wind loads on structures are given by EN 1991-1-4 and National Annex EN 1991-1-4/NA. The wind load calculation is based on the specific wind situation in the given area or specific location where the structures are built. The resulting wind load values are affected by the following factors: site-specific wind conditions, terrain roughness and aerodynamic properties of the structure shapes.

The character of the wind flow around the objects determines the Reynolds number

$$
\operatorname{Re}=d \cdot v / v
$$

Where $d$ - is the characteristic size of the obstacle, $v$ - is flow velocity, $v=1.5 \cdot 10^{-5}\left[\mathrm{~m}^{2} / \mathrm{s}\right]$ is kinematic viscosity.

In the case of model similarity of real and reduced construction, it is necessary to keep the minimum value of $\operatorname{Re}=1 \cdot 10^{4}$, where the distribution of wind pressures on the real object and the model is identical.

\subsection{Wind velocity and pressure}

The basic characteristics of turbulent wind flow are mean wind velocity, peak velocity pressure and resulting wind pressure at the area.

Mean wind velocity at height $z$ depends on terrain, and reference wind velocity

$$
v_{\mathrm{m}}(z, t)=\frac{1}{T} \int_{0}^{T} v(z, t) d t=v_{\mathrm{m}}(z)=0,19\left(z / z_{0, \mathrm{II}}\right)^{0,07} \ln \left(z / z_{0}\right) \cdot v_{\mathrm{b}}
$$

where $v_{\mathrm{b}}$ - is reference wind velocity, $\mathrm{z}_{0, \mathrm{II}}$ - roughness length.

Peak velocity pressure $\mathrm{q}_{\mathrm{p}}(\mathrm{z})$ takes into account turbulence intensity $I_{\mathrm{v}}(z)$

$$
\begin{aligned}
& q_{\mathrm{p}}(z)=\left[1+7 I_{\mathrm{v}}(z)\right] \cdot 1 / 2 \cdot \rho \cdot v_{\mathrm{m}}^{2}(z) \\
& I_{\mathrm{v}}(z)=\frac{k_{I}}{c_{0}(z) \cdot \ln \left(z / z_{0}\right)}
\end{aligned}
$$

External wind pressure depends on external wind pressure coefficient $c_{p e}$ and peak pressure

$$
w_{e}=c_{p e} \cdot q_{p}(\mathrm{z})
$$

The external wind pressure coefficients $c_{p e}$ for multispan and monopitch roofs are given in part 7 in [1] (see Fig. 1. and Fig. 2.).

\subsection{Wind flow around a group of object}

The wind load distribution on the multi-span roofs hall with dimensions of $33 \times 36 \mathrm{~m}$ as well as the influence of the three cylindrical tanks on this load had been tested. Three cylindrical tanks with a diameter $d=9.52 \mathrm{~m}$ were standing in a row at a distance of $1.98 \mathrm{~m}$ from each other and the distance from the hall was only $1.69 \mathrm{~m}$. The roof with low slope as well as the wall just behind the cylinders at various places had been tested. The standard values for the windward part of the roof for a given slope without the influence of surrounding objects are given in Table 1. The largest suctions are in Fig. 2 in zone F for both wind directions $0^{\circ}$ and $180^{\circ}$. We investigated the effect of wind direction changes on external wind pressure coefficients in two rows on the roof and also on the wall. The height 
of the hall was $11 \mathrm{~m}$ and the cylindrical tank with the dome was $17.16 \mathrm{~m}$ high. The hall together with the tanks are the objects of the nuclear power plant, where high safety is required and for this reason we also examined the effects of wind on the structures. The analysis of wind loads on tanks was described in article [6]. Subsequently we tested the near standing hall.

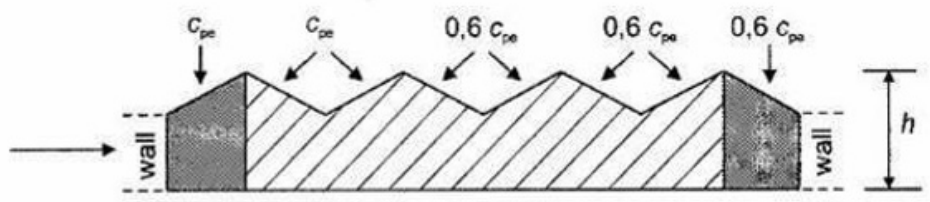

Fig. 1. External wind pressure coefficients for a multispan roof in EN 1991-1-4.

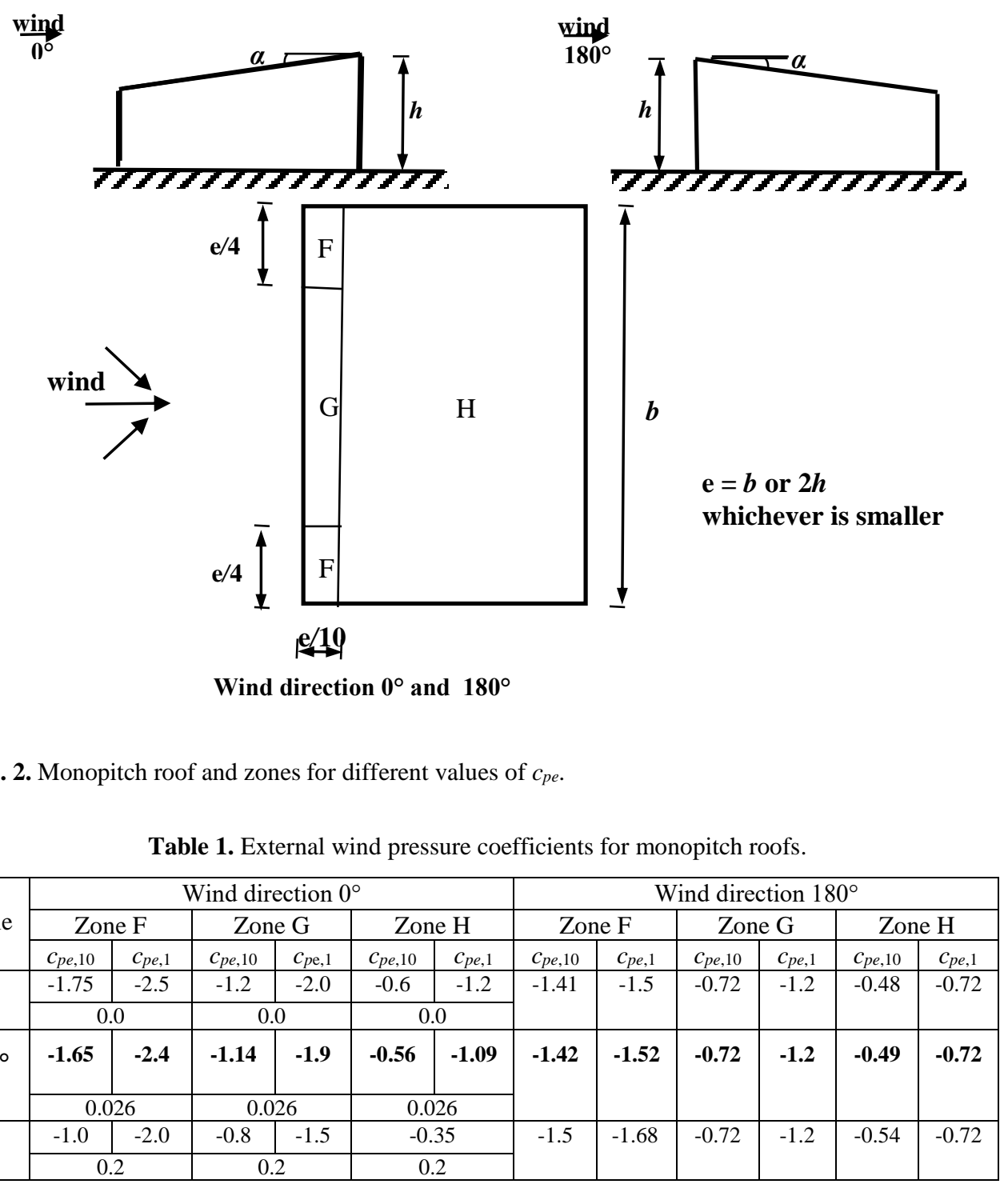




\section{Experimental investigation of external wind pressure coefficient}

\subsection{Boundary layer wind tunnel and model of area in a power plant}

In the BLWT wind tunnel in Bratislava (see Fig. 3.), we tested according to ACSE [4] and [5], the hall and cylindrical tanks in the rear measuring space, at different wind speeds and directions.

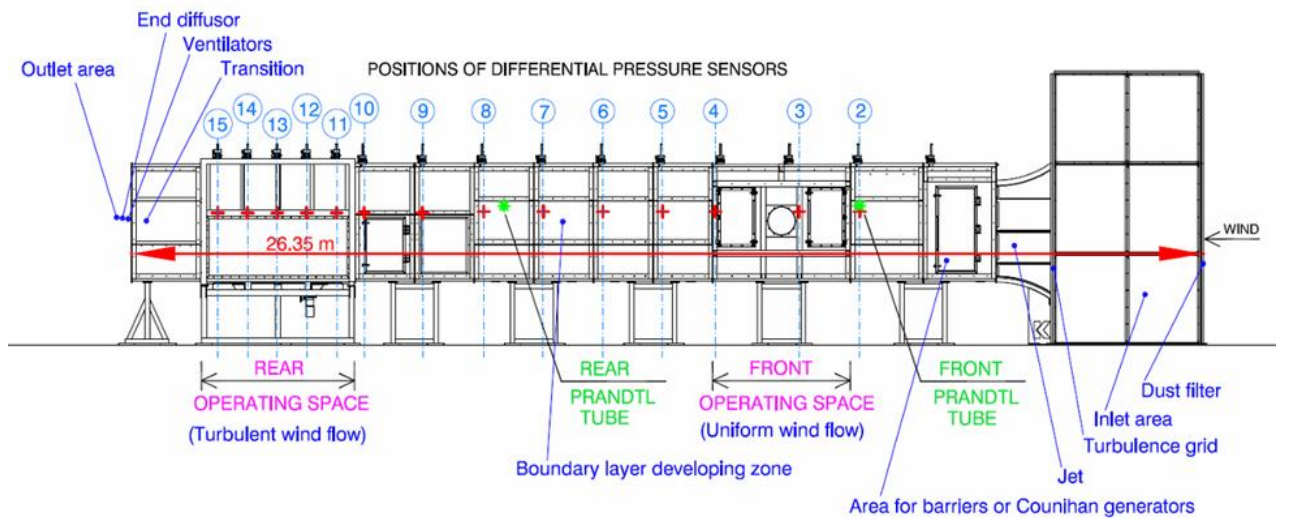

Fig. 3. BLWT wind tunnel scheme.

The hall and circular cylinders models in 1: 59.5 scale were placed behind the modeled and experimentally verified boundary layer [2] of terrain category between III - IV. The terrain with the corresponding roughness length $z_{0}=0.7$ represents the built-up area. The flow velocities were set using LabVIEW, which controls the tunnel depending on the frequency of the inverters and had values of 20 and $24 \mathrm{~Hz}$, which corresponded to the mean values of the reference wind speeds on the top of cylinders $h=27 \mathrm{~cm}$. The reference wind speeds had values $v_{\text {ref }, 1}=9.57 \mathrm{~m} / \mathrm{s}$ and $v_{\text {ref }, 2}=11.73 \mathrm{~m} / \mathrm{s}$ depending on barometric pressure, temperature and air density.

External wind pressures corresponding to the reference speed at the top of the model were measured at two altitude levels along the roof and along the wall. The total number of sampling points was 64 . The sampling points on the roof and wall are shown in Figs. 4, 5, 6.

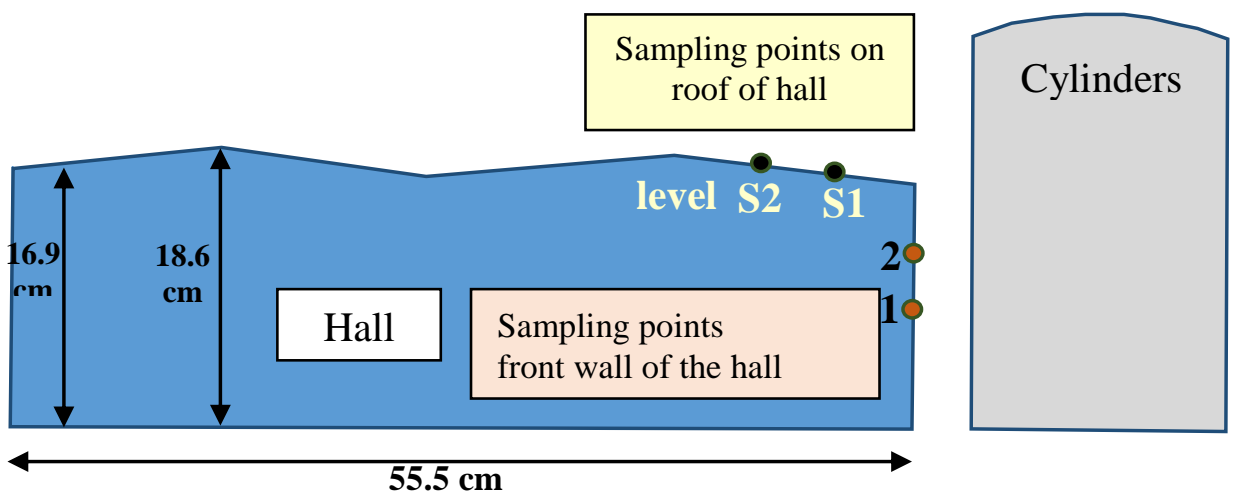

Fig. 4. Location of sampling points on the hall. 


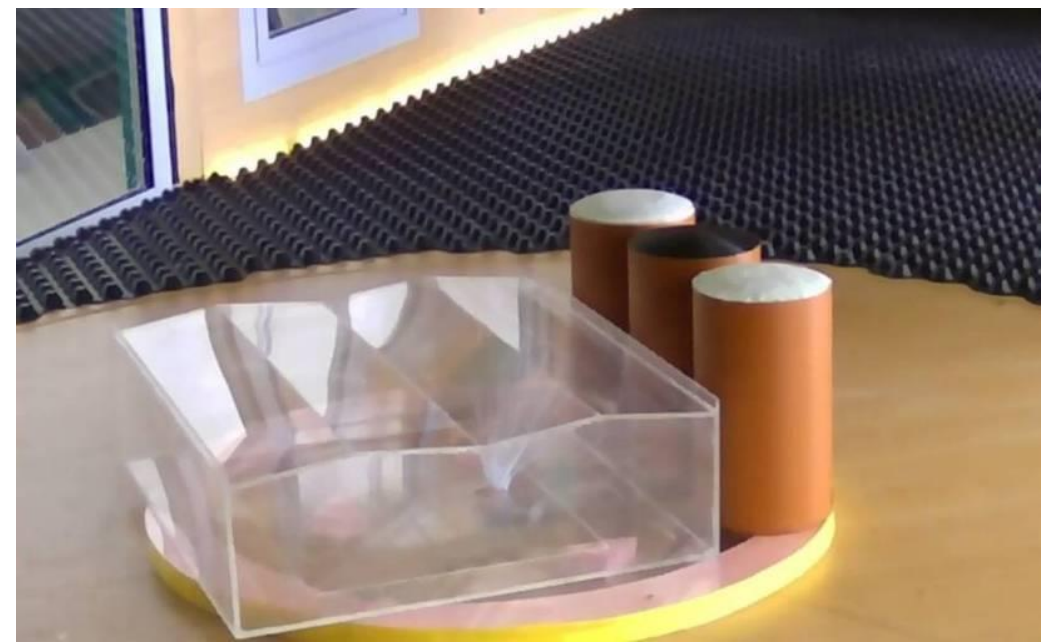

Fig. 5. Model on rotating table, wind direction $45^{\circ}$.

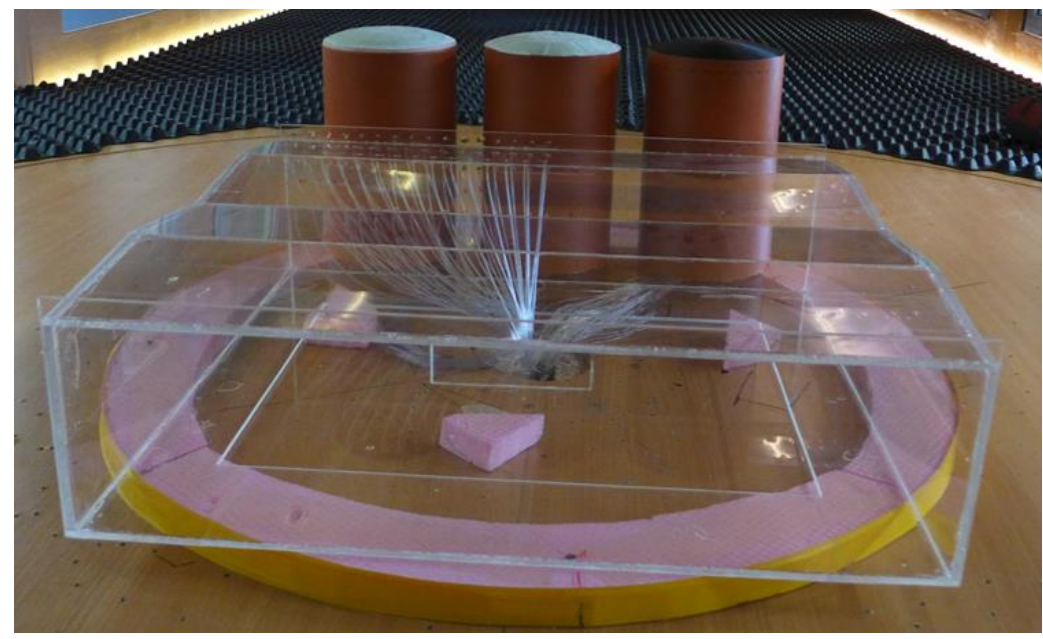

Fig. 6. Detail view of sampling points on hall.

The models were placed on a turntable and rotated by $15^{\circ}$ to simulate a change of the wind direction acting on the objects.

\subsection{Evaluation of external wind pressure coefficients of a hall}

The value of external wind pressure coefficient was calculated by Eq. 6

$$
c_{\mathrm{p}}=\frac{\Delta p}{p_{\text {dyn }}\left(z_{\text {ref }}\right)}=\frac{p(t)-p_{0}}{1 / 2 \cdot \rho \cdot \bar{v}^{2}\left(z_{\text {ref }}\right)}
$$

where $p(t)$ is the wind pressure in measuring point on the surface of the model and $p_{0}$ is static pressure of undisturbed flow measured by Prandtl probe. Dynamic pressure of the mean wind velocity $p_{\text {dyn }}$ was considered in reference height (in our case, reference height was equalled to the height of the top of cylindrical tank).

Distribution of external wind pressure coefficients for the roof and wall was obtained from the repeated experimental measurements. 
If the wind pressure is negative, the hall is loaded by suction, at a positive value it is the wind pressure. The resulting external wind pressure and suction coefficients that take into account important wind directions are shown in Figs. 7-10.

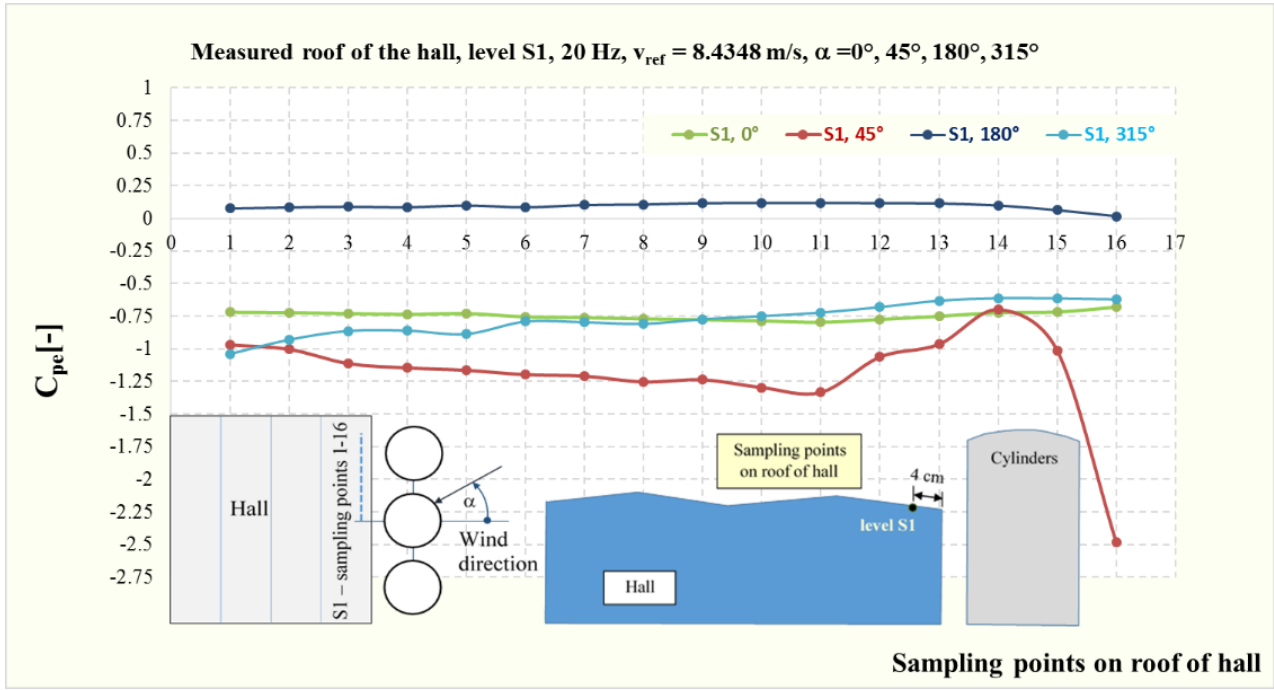

Fig. 7. Resulting external wind pressure coefficients for the roof of a hall, level S1.

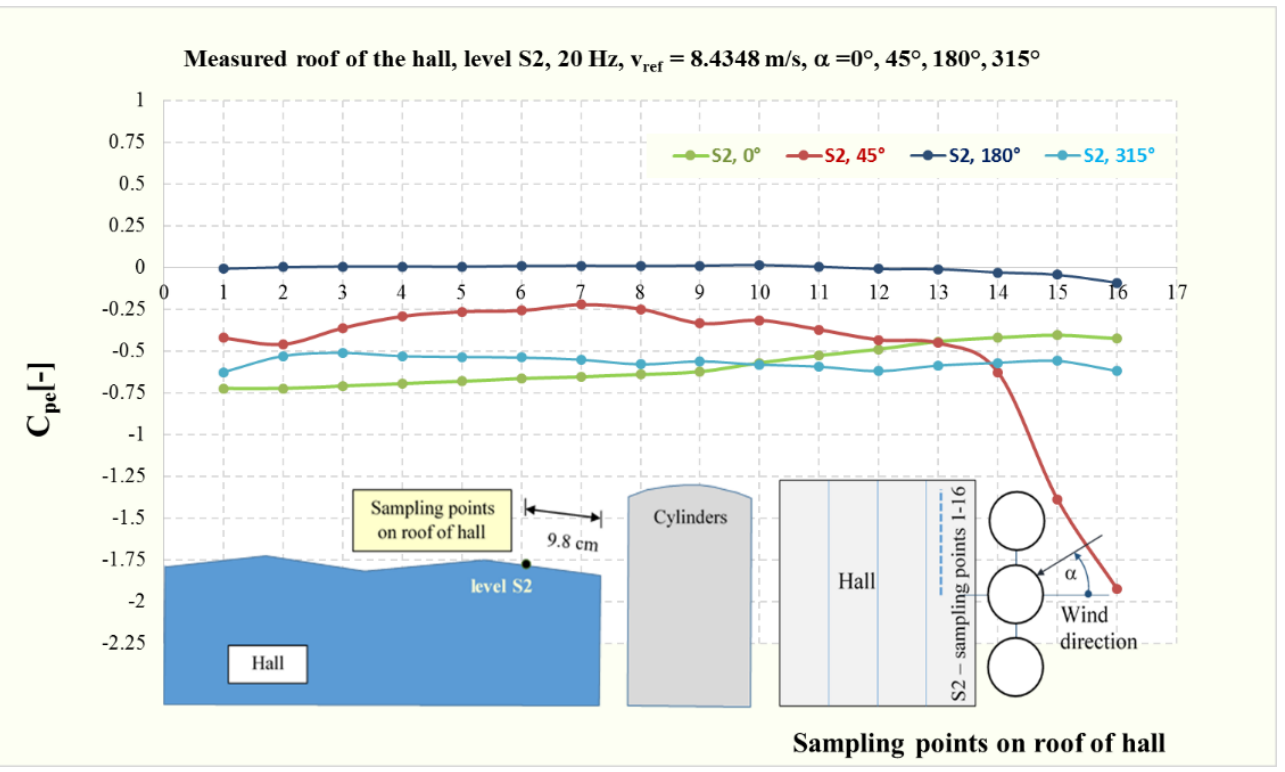

Fig. 8. Resulting external wind pressure coefficients for the roof of a hall, level S2. 


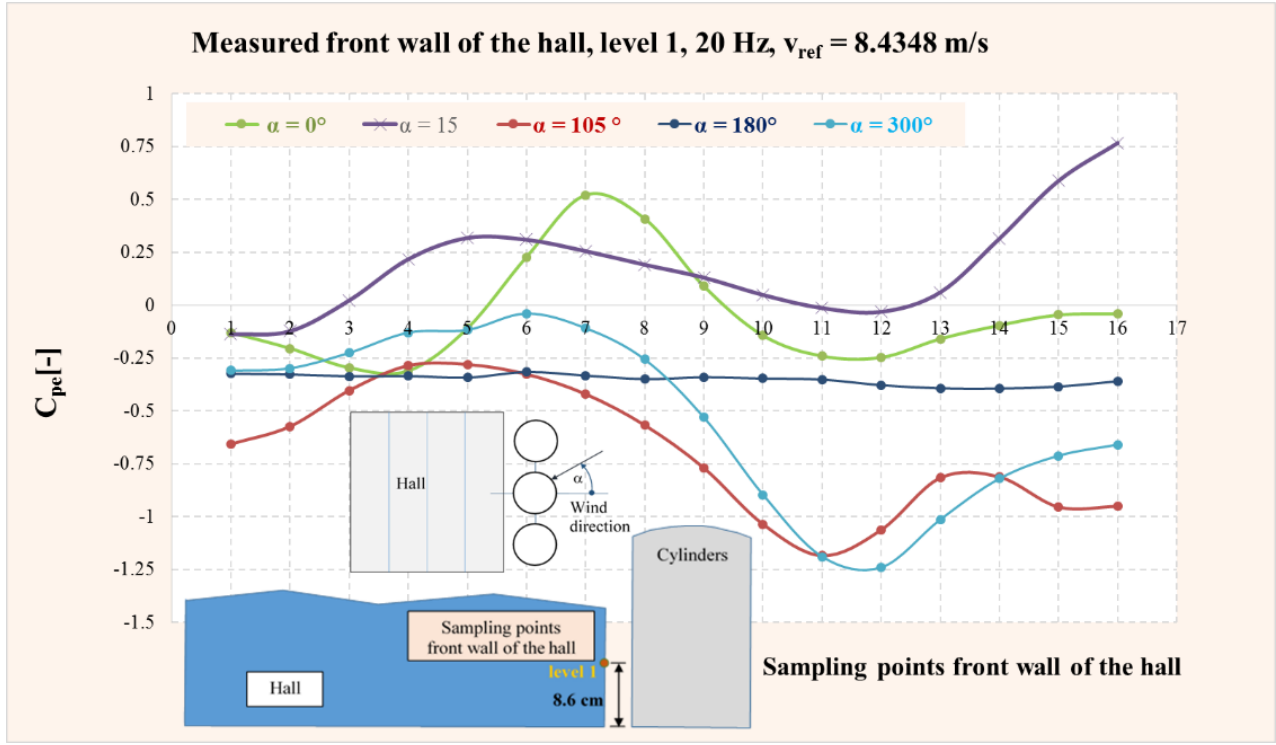

Fig. 9. Resulting external wind pressure coefficients for the front wall, level 1.

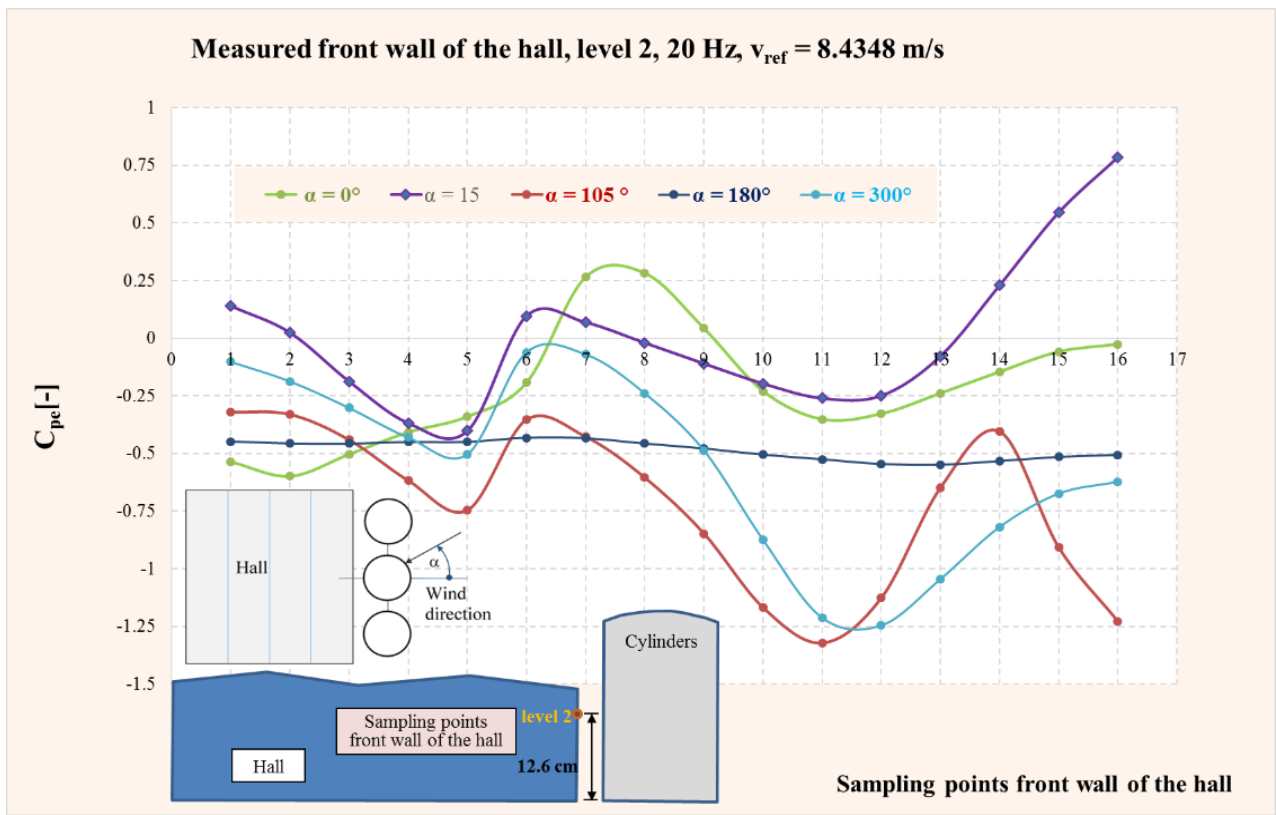

Fig. 10. Resulting external wind pressure coefficients for the front wall, level 2.

\section{Conclusion}

The aim of the experimental research was to determine values of the external wind pressure coefficients on multispan roofs and the front wall. We verified whether the values in the most stressed areas did not exceed the standard values for the stand-alone hall. 
In the wind direction $45^{\circ}$, the value of the local external wind coefficient at the edge at point 16 in row S2 slightly exceeded the standard value of -2.4 and reached the suction value of -2.5 . At wind direction $180^{\circ}$, the wind pressure values on the roof at the S1 and S2 levels were very low compared to the standard suction values. Cylindrical tanks modify the wind flow on the roof. The external wind pressure coefficients on the wall of the hall did not exceed the standard value of 0.8 and reached the maximum value of 0.75 . The suction on the wall has reached -1.25 , which is lower than the local coefficient at the wall edge 1.4. It can be stated that, in spite of the cylindrical tanks which are standing close to the hall, the stresses on the roof and wall did not exceed the local wind coefficients according to EN 1991-1-4, which had to be verified.

Presented results have been arranged due to the research supported by the Slovak Scientific Grant Agency, projects VEGA No. 1/0453/20 and KEGA No. 025 STU-4/2019.

\section{References}

1. EN 1991-1-4 Eurocode 1. Actions on structures, Part 1-4: General actions, Wind actions (2006)

2. O. Hubova, P. Lobotka, Natural Simulations in the BLWT STU Wind Tunnel. ATF $3^{\text {rd }}$ Conference. E - Book, 78-84 (2014)

3. O. Hubova, The effect of the wind on the structure, Slovak Journal of Civil Engineering 2007/3, XV (2007)

4. ASCE Manuals and Reports on Engineering Practice, no. 67, Wind Tunnel Studies of Buildings and Structures. Library of Congress Catalog Card No.: 98-44103, USA (1999)

5. G. Solari, Gust buffeting. I: Peak wind velocity and equivalent pressure, J. Struct. Engng., ASCE, 119, 2, 365-382 (1993)

6. O. Hubova, I. Veghova, Influence of the near standing hall for wind flowing around group of circular cylinders, SPACE (2019) 